\title{
Article \\ Survey of Volvariella (Agaricales, Basidiomycota) including Two New Species, V. neovolvacea and V. thailandensis, from Northern Thailand
}

\author{
Jaturong Kumla ${ }^{1,2, *}$, Nakarin Suwannarach ${ }^{1,2} \mathbb{D}$, Nopparat Wannathes ${ }^{3}$ and Saisamorn Lumyong ${ }^{1,2,4}$ \\ 1 Research Center of Microbial Diversity and Sustainable Utilization, Chiang Mai University, \\ Chiang Mai 50200, Thailand; nakarin.su@cmu.ac.th (N.S.); saisamorn.1@cmu.ac.th (S.L.) \\ 2 Department of Biology, Faculty of Science, Chiang Mai University, Chiang Mai 50200, Thailand \\ 3 Microbiology Program, Faculty of Science and Technology, Pibulsongkram Rajabhat University, \\ Phitsanulok 65000, Thailand; wnopparat@psru.ac.th \\ 4 Academy of Science, The Royal Society of Thailand, Bangkok 10300, Thailand \\ * Correspondence: jaturong.kumla@cmu.ac.th; Tel.: +66-87-192-6527
}

Citation: Kumla, J.; Suwannarach, N.; Wannathes, N.; Lumyong, S. Survey of Volvariella (Agaricales, Basidiomycota) including Two New Species, $V$. neovolvacea and $V$. thailandensis, from Northern Thailand. Diversity 2022, 14 161. https://doi.org/10.3390/ d14030161

Academic Editor: Ipek Kurtboke

Received: 28 January 2022

Accepted: 21 February 2022

Published: 24 February 2022

Publisher's Note: MDPI stays neutral with regard to jurisdictional claims in published maps and institutional affiliations.

Copyright: (C) 2022 by the authors. Licensee MDPI, Basel, Switzerland. This article is an open access article distributed under the terms and conditions of the Creative Commons Attribution (CC BY) license (https:// creativecommons.org/licenses/by/ $4.0 /)$

\begin{abstract}
During the period from 2018 to 2020, a survey of macrofungi in northern Thailand was conducted and seven specimens of Volvariella were collected. The morphological characteristics and phylogenetic analyses of the internal transcribed spacers (ITS) and large subunit (nrLSU) of the nuclear ribosomal DNA (rDNA) sequence data indicated that three specimens belonged to $V$. bombycina and $V$. volvacea. Four other specimens were distinct from all other known species within the genus Volvariella. We described these specimens as two new species, namely $V$. neovolvacea and $V$. thailandensis. Comprehensive descriptions, illustrations, line drawings, and a phylogenetic tree are provided to show the position of the two new species. The comparisons between morphologically similar and phylogenetically related species are also discussed.
\end{abstract}

Keywords: gill fungi; phylogeny; saprophytic fungi; taxonomy; tropical area

\section{Introduction}

The genus Volvariella was first proposed in 1898 with $V$. argentina as the species type. Volvariella species are known to be widely distributed throughout Africa, Asia, Australasia, Europe, and America [1-8]. They are recognized as saprobes and are mostly found on the ground in grasslands or forests. They have also been found to grow on dead wood and on the litter of the forest floor [7-10]. Volvariella has been characterized by pluteoid basidiomata, the presence of volva, a pink to pinkish brown spore print, ovoid to elongated basidiospores with a smooth surface, and by appearing inamyloid [10-12]. Currently, $V$. volvacea is commercially cultivated as an edible mushroom in Asia, especially in China, India, the Philippines, and Thailand [13,14]. Volvariella has been placed within the families Amanitaceae [15], Agaricaceae [16], and Pluteaceae [11] of the order Agaricales. In 2006, this genus was placed in the family Pluteaceae based on phylogenetic analyses [17]. However, a later molecular study conducted by Justo et al. [18] separated the Volvariella species into two genera, namely Volvariella and Volvopluteus. Volvopluteus was placed in the family Pluteaceae; however, Volvariella formed a more distant position from the family Pluteaceae and was more closely related to genera Cantharocybe and Cuphophyllus in the family Hygrophoraceae. Therefore, Volvariella should be treated as incertae sedis of the order Agaricales [18]. According to the Dictionary of Fungi by Kirk et al. [6] and He et al. [19], about 50 species of Volvariella have been reported worldwide. However, there are 143 records of Volvariella names in the Index Fungorum (Index Fungorum 2021, accessed on February 2022), including specific and infraspecific taxa, illegitimate names, invalid names, and names widely accepted as taxonomic synonyms. These names can include species that have not yet been welldocumented and may also include misidentifications. 
Only eight species of Volvariella, namely $V$. bombycina, $V$. cubensis, $V$. hypopithys, $V$. pseudovolvacea, $V$. pulla, V. pusilla, V. rostricystidiata, and $V$. volvacea, have been previously recorded from Thailand $[6,20,21]$. Many studies have proposed that Thailand has proven to be a hot spot for novel species discovery [22]. Recently, this has been further evidenced by the discovery of many new species of macrofungi [23-25]. In this study, we found seven Volvariella specimens during our investigations of macrofungi in northern Thailand during the period from 2018 to 2020. Amongst these, two new species, $V$. neovolvacea and $V$. thailandensis, were introduced based on studies of their morphological and molecular data. We used a combined analysis of ITS and nrLSU of the rDNA sequence data to confirm the taxonomic status and infer the phylogenetic position of these two species.

\section{Materials and Methods}

\subsection{Sample Collection}

Volvariella was surveyed at Chiang Mai, Mae Hong Son, and Sukhothai provinces, Thailand during the rainy seasons of the years 2018 to 2020. The collection in Sukhothai province was granted permission from the Department of National Parks, Wildlife and Plant Conservation, Bangkok, Thailand (document No. 0907.4/13696). Basidiomata were collected and wrapped in aluminum foil and kept in plastic boxes. Specimens were dried in a hot air oven at $45^{\circ} \mathrm{C}$ until they were completely dried. They were then kept in a plastic zip-locked bag and deposited in the Herbarium of Bangkok Forest Herbarium (BKF), Bangkok, Thailand and Sustainable Development of Biological Resources (SDBR-CMU), Faculty of Science, Chiang Mai University, Thailand. MycoBank numbers are provided [26].

\subsection{Morphological Observation}

Macromorphological data were derived from fresh specimens. Color names and codes followed Kornerup and Wanscher [27]. Micromorphological data were derived from dried specimens that were rehydrated in $95 \%$ ethanol, followed by distilled water, $5 \% \mathrm{KOH}$, Congo red solution, or Melzer's reagent. Micromorphological characteristics were examined under a light microscope (Nikon Eclipse Ni U, Tokyo, Japan). Size data of the anatomical structure (e.g., basidiospores, basidia, and cystidia) are based on at least 50 measurements of each structure using the Tarosoft (R) Image Frame Work program. For basidiospore statistics, measurements are presented as $(a) b-c-d(e)$, where ' $a$ ' and 'e' are the extreme values, ' $b-d$ ' is the range containing $90 \%$ of all values, and ' $c$ ' is the average. $Q$ represents the ratio of length divided by the width of each basidiospore and $Q$ represents the average $Q$ of all specimens \pm standard deviation.

\subsection{DNA Extraction, Amplification and Sequencing}

Genomic DNA of dry specimens (5 mg) was extracted using a Genomic DNA Extraction Mini-Kit (FAVORGEN, Ping-Tung, Taiwan). The ITS region was amplified by polymerase chain reaction (PCR) using ITS4 and ITS5 primers [28] under the following thermal conditions: $95^{\circ} \mathrm{C}$ for $2 \mathrm{~min}, 30$ cycles of $95^{\circ} \mathrm{C}$ for $30 \mathrm{~s}, 50{ }^{\circ} \mathrm{C}$ for $30 \mathrm{~s}, 72{ }^{\circ} \mathrm{C}$ for $1 \mathrm{~min}$, and $72{ }^{\circ} \mathrm{C}$ for $10 \mathrm{~min}$ on a peqSTAR thermal cycler (PEQLAB Ltd., Fareham, UK). The nrLSU region was amplified with LROR and LRO5 primers [29] under the following thermal conditions: $94{ }^{\circ} \mathrm{C}$ for $2 \mathrm{~min}, 30$ cycles of $95{ }^{\circ} \mathrm{C}$ for $30 \mathrm{~s}, 52{ }^{\circ} \mathrm{C}$ for $30 \mathrm{~s}, 72{ }^{\circ} \mathrm{C}$ for $1 \mathrm{~min}$, and $72{ }^{\circ} \mathrm{C}$ for $10 \mathrm{~min}$. PCR products were checked on $1 \%$ agarose gels stained with ethidium bromide under UV light. PCR products were purified using a PCR Clean-Up Gel Extraction NucleoSpin ${ }^{\circledR}$ Gel and PCR Clean-Up Kit (Macherey-Nagel, Düren, Germany) following the manufacturer's protocol. The purified PCR products were directly sequenced. Sequencing reactions were performed and the sequences were automatically determined in the genetic analyzer at 1st Base Company (Kembangan, Malaysia) using the PCR primers mentioned above. 


\subsection{Sequence Alignment}

Analysis of the sequences was conducted by similarity searches using the BLAST program available at NCBI (http:/ / blast.ncbi.nlm.nih.gov, accessed on 21 December 2021). The sequences from this study, previous studies, and the GenBank database (with $\geq 60 \%$ query coverage and $\geq 85-100 \%$ sequence similarity) were selected and listed in Table 1 . Multiple sequence alignment was performed with MUSCLE [30]. The alignments were manually checked. The combined ITS and nrLSU alignment was deposited in TreeBASE under the study ID number 29067.

Table 1. Details of sequences used in the molecular phylogenetic analysis.

\begin{tabular}{|c|c|c|c|c|c|}
\hline \multirow{2}{*}{ Taxa } & \multirow{2}{*}{ Strain/Voucher } & \multirow{2}{*}{ Country } & \multicolumn{2}{|c|}{ GenBank Accession Number } & \multirow{2}{*}{ Reference } \\
\hline & & & ITS & nrLSU & \\
\hline Cantharocybe virosa & SDBR-CMUNK0280 & Thailand & MG694692 & MG694690 & [31] \\
\hline Cuphophyllus yacurensis ${ }^{\mathrm{T}}$ & QCAM5891 & Ecuador & NR166388 & KY780119 & [32] \\
\hline Volvariella aethiops & $\mathrm{K}(\mathrm{M}): 195631$ & United Kingdom & MZ159529 & - & Unpublished \\
\hline Volvariella bombycina & AJ244 & Spain & HM562212 & HM562256 & {$[18]$} \\
\hline Volvariella bombycina & SDBR-CMUNK0726 & Thailand & OM417508 & OM373644 & This study \\
\hline Volvariella bombycina & xj2018071604 & China & MT351048 & - & Unpublished \\
\hline Volvariella caesinotincta & MA54717 & Spain & HM562211 & HM562255 & [18] \\
\hline Volvariella diplasia & CBS 355.64 & India & MH858454 & MH870086 & {$[21]$} \\
\hline Volvariella dunensis & JAC10587 & New Zealand & MN738630 & MN738630 & Unpublished \\
\hline Volvariella dunensis & SCM3513 & Spain & JF415140 & - & [33] \\
\hline Volvariella guttulosa ${ }^{\mathrm{T}}$ & LE 313326 & Vietnam & - & NG068890 & [4] \\
\hline Volvariella hypopithys & TO AV137 & Italy & HM246492 & HM246488 & Unpublished \\
\hline Volvariella krizii $\mathrm{T}^{\mathrm{T}}$ & PR1516257 & Czech Republic & - & MK770133 & [34] \\
\hline Volvariella krizii & BRNM 290000 & Czech Republic & - & MK770133 & [34] \\
\hline Volvariella lepiotospora & AJ155 & USA & HM562214 & HM562259 & Unpublished \\
\hline Volvariella lepiotospora & FLAS-F-61505 & USA & MH281874 & - & Unpublished \\
\hline Volvariella morozovae $^{\mathrm{T}}$ & LE 313229 & Vietnam & MF377507 & MF377508 & [32] \\
\hline Volvariella morozovae & LE 313323 & Vietnam & MK882995 & - & [32] \\
\hline Volvariella murinella & GLM:GLM-F42624 & Germany & MK412400 & MK412400 & Unpublished \\
\hline Volvariella murinella & GLM:GLM-F43392 & Germany & MK412361 & - & Unpublished \\
\hline Volvariella neovolvacea $^{\mathrm{T}}$ & SDBR-CMUNK0758 & Thailand & OM417503 & OM373653 & This study \\
\hline Volvariella neovolvacea & SDBR-CMUNK0760 & Thailand & OM417505 & OM417507 & This study \\
\hline Volvariella nivea ${ }^{\mathrm{T}}$ & GDGM25489 & China & FJ749127 & - & [35] \\
\hline Volvariella niveosulcata $^{\mathrm{T}}$ & LE 313329 & Vietnam & MK882996 & MK883002 & {$[4]$} \\
\hline Volvariella nullicystidiata & SP393639 & Brazil & EU920671 & EU920670 & [3] \\
\hline Volvariella perciliata & SP393635 & Brazil & EU920672 & EU920668 & [3] \\
\hline Volvariella ptilotricha ${ }^{\mathrm{T}}$ & LE 313324 & Vietnam & NR164612 & MK882997 & {$[4]$} \\
\hline Volvariella pulla ${ }^{\mathrm{T}}$ & LE 313325 & Vietnam & NR164613 & MK883003 & [4] \\
\hline Volvariella pulla & MFLU 19-1534 & Thailand & MT074696 & - & [6] \\
\hline Volvariella pusilla & TO AV139 & Italy & HM246494 & HM246479 & Unpublished \\
\hline Volvariella rava ${ }^{\mathrm{T}}$ & GDGM41955 & China & KP784686 & - & [36] \\
\hline Volvariella reidii & F1-1.1 & Finland & MK770139 & MK770131 & {$[34]$} \\
\hline Volvariella reidii & F1-1.2 & Finland & MK770140 & MK770132 & [34] \\
\hline Volvariella rostricystidiata $^{\mathrm{T}}$ & MFLU 19-1528 & Thailand & MT074694 & - & [6] \\
\hline Volvariella rostricystidiata & MFLU 19-1531 & Thailand & MT074695 & - & [6] \\
\hline Volvariella cf. sathei & Hama193 & Niger & KF926663 & - & [37] \\
\hline Volvariella sathei & AMH 9436 & India & JN792550 & - & [38] \\
\hline Volvariella strangulata & TO AV141 & Italy & HM246493 & HM246484 & Unpublished \\
\hline Volvariella surrecta & GLM:GLM-F61563 & Germany & MK412358 & MK412358 & Unpublished \\
\hline Volvariella surrecta & AJ55 & Spain & HM562213 & HM562254 & [18] \\
\hline Volvariella taylorii & AJ54 & Portugal & HM562210 & HM562260 & [18] \\
\hline Volvariella terrea & LUG11010 & France & JF415141 & - & {$[33]$} \\
\hline Volvariella thailandensis $\mathrm{T}$ & SDBR-CMUNK0957 & Thailand & OM417510 & OM417509 & This study \\
\hline Volvariella thailandensis & SDBR-CMUNK0958 & Thailand & OM417510 & OM386669 & This study \\
\hline
\end{tabular}


Table 1. Cont.

\begin{tabular}{|c|c|c|c|c|c|}
\hline \multirow{2}{*}{ Taxa } & \multirow{2}{*}{ Strain/Voucher } & \multirow{2}{*}{ Country } & \multicolumn{2}{|c|}{ GenBank Accession Number } & \multirow{2}{*}{ Reference } \\
\hline & & & ITS & nrLSU & \\
\hline Volvariella turcica $^{\mathrm{T}}$ & OKA-TR17.1 & Turkey & MK770135 & MK770128 & [34] \\
\hline Volvariella turcica & OKA-TR17.2 & Turkey & MK770136 & MK770129 & [34] \\
\hline Volvariella volvacea & $\mathrm{H} 6$ & Nigeria & KC894929 & - & [39] \\
\hline Volvariella volvacea & OE-273 & India & KC14211 & - & Unpublished \\
\hline Volvariella volvacea & BKF10217 & Thailand & MN492647 & OM373563 & This study \\
\hline Volvariella volvacea & SDBR-CMUNK505 & Thailand & OM417506 & OM373623 & This study \\
\hline
\end{tabular}

Superscript “T” represents type species. "-" represents the absence of sequence data in GenBank database.

\subsection{Phylogenetic Analyses}

Phylogenetic analysis was carried out based on the combined dataset of ITS and nrLSU. Cantharocybe virosa and Cuphophyllus yacurensis were used as the outgroup. A phylogenetic tree was constructed under maximum likelihood (ML) and Bayesian inference (BI) methods. ML analysis was carried out using RAxML-HPC2 version 8.2.10 [40] on the CIPRES web portal [41] under the GTRCAT model with 25 categories and 1000 bootstrap replications [42]. $\mathrm{BI}$ analysis was performed with MrBayes v3.2.6 [43]. The best substitution models for ML and $\mathrm{BI}$ analyses were estimated by Akaike information criterion (AIC) in jModelTest 2.1.10 [44]. The best substitution models were GTR+I+G for ITS and nrLSU. For the BI analysis, six simultaneous Markov chains were run for one million generations with random initial trees, and every 1000 generations were sampled. The burn-in was set to discard the first 2000 of the trees, and the remaining trees were used to construct the $50 \%$ majority-rule consensus phylogram with calculated Bayesian posterior probabilities (PP). Branches with bootstrap support (BS) and PP values greater than or equal to $70 \%$ and 0.95 , respectively, were considered to be significantly supported $[45,46]$. The tree topologies were visualized in FigTree v1.4.0 [47].

\section{Results}

\subsection{Sample Collection and Morphological Observation}

A total of seven specimens of Volvariella were obtained in this study. Morphologically, the specimen voucher SDBR-CMU505 collected from Chiang Mai province and the voucher BKF10217 collected from Sukhothai province were found to be similar to the morphological descriptions of $V$. volvacea. Notably, SDBR-CMUNK0726 collected from Mae Hong Son province was initially identified as belonging to $V$. bombycina. However, the morphological characteristics of the other four specimen vouchers (SDBR-CMUNK0758, SDBR-CMUNK0760, SDBR-CMUNK0957, and SDBR-CMUNK0958) collected from Chiang Mai province differed from the previously known descriptions of Volvariella species. These four specimen vouchers were representative of a potential new species. Therefore, the identification was then further confirmed by the multi-gene phylogenetic analyses of ITS and nrLSU sequences.

\subsection{Phylogenetic Results}

The sequences of seven specimens were deposited in the GenBank database (Table 1). The alignment of a combination of ITS and nrLSU genes contained 1989 characters, including gaps (ITS: 1-1039 and nrLSU: 1040-1989). RAxML analysis of the combined dataset yielded the best scoring tree with a final ML optimization likelihood value of $-13,839.8771$. The matrix contained 1030 distinct alignment patterns with $49.73 \%$ undetermined characters or gaps. The estimated base frequencies were recorded as follows: $\mathrm{A}=0.2255$, $\mathrm{C}=0.2599, \mathrm{G}=0.2697, \mathrm{~T}=0.2448$; substitution rates $\mathrm{AC}=1.1148, \mathrm{AG}=2.3791, \mathrm{AT}=0.9787$, $\mathrm{CG}=0.8637, \mathrm{CT}=5.0398, \mathrm{GT}=1.0000$. The gamma distribution shape parameter alpha was equal to 0.3033 , and the tree length was equal to 4.9110 . In addition, the final average standard deviation of the split frequencies at the end of the total MCMC generations was 
calculated as 0.00826 through BI analysis. Phylograms of the ML and BI analyses were similar in terms of topology (data not shown). Therefore, the phylogram obtained from the ML analysis was selected and presented in this study. The phylogram was comprised of 50 specimens of Volvariella and two specimens of the outgroup (Cantharocybe virosa SDBRCMUNK0280 and Cuphophyllus yacurensis QCAM5891) (Figure 1). A phylogram clearly separated our four specimens into two monophyletic clades with high support values ( $\mathrm{BS}=100 \%$ and $\mathrm{PP}=1.0$ ). Accordingly, they were clearly distinguished from the previously known species of Volvariella. Two specimen vouchers, namely SDBR-CMUNK0758 and SDBR-CMUNK0760 (introduced as $V$. thailandensis), formed a sister clade to $V$. sathei with high support $(\mathrm{BS}=100 \%$ and $\mathrm{PP}=1.0$ ). Moreover, the two specimens in this study, SDBRCMUNK957 and SDBR-CMUNK95 (described here as $V$. neovolvacea), formed a sister clade to $V$. thailandensis and $V$. sathei with $91 \%$ BS and 1.0 PP support values. Additionally, the other obtained specimen vouchers, SDBR-CMUNK505 and SDBR-NW1022, were placed within the same clade of $V$. volvacea, while the specimen voucher SDBR-CMUNK0726 was placed within the clade of $V$. bombycina.

\subsection{Taxonomic Description of New Species}

Volvariella neovolvacea J. Kumla, N. Suwannarach and S. Lumyong, sp. nov. Figure 2. MycoBank: 842646.

Diagnosis: Similar to $V$. volvacea but differing in a wider basidiospores.

Etymology: Name derived from the macromorphological similarity to $V$. volvacea.

Holotype: THAILAND, Chiang Mai province, Chiang Mai University campus, $18^{\circ} 48^{\prime} 6^{\prime \prime} \mathrm{N}$ $98^{\circ} 57^{\prime} 23^{\prime \prime}$ E, elevation $331 \mathrm{~m}$, on soil in grassland, July 2020, J. Kumla and N. Suwannarach, SDBR-CMUNK0758.

Gene sequences (from holotype): OM417503 (ITS) and OM373653 (nrLSU).

Pileus 65-80 mm in diameter, convex, umbo and slightly inflexed margin, brownish orange (5C3) to greyish brown (6E3-7E3), non-hygrophanous, with fibrillose to appressed squamulose surface; margin decurved to straight, thin, crenulate; context soft, white (4A1) to light yellow (4A5). Lamellae free, ventricose, close, moderately thin, soft, orange white (6A2) turning pinkish white (7A2) with age; edge finely fimbriate, concolorous with faces; lamellulae present, very variable in length, mostly in one tier. Stipe 85-110 × 20-25 mm, central, tapered from the base to apex, solid, grey (6B1), entirely pubescent; context white (4A1) to light yellow (4A5); annulus absent. Volva 30-50 mm high, thick, mostly free, saccate, fragile, white (6A1) to greyish brown (6E3). Spore print pinkish (7A2).

Basidiospores (6.5)6.7-7-7.5(8) × (5)5.2-5.5-6(7) $\mu \mathrm{m}(\mathrm{n}=50), \mathrm{Q}=1.14-1.45, \mathrm{Q}=1.28 \pm 0.1$, broadly ellipsoid to ellipsoid, thick-walled, hyaline, inamyloid. Basidia 27-40 × 7.5-11 $\mu \mathrm{m}$, narrowly to broadly clavate, hyaline, 4-spored; sterigmata up to $2.5 \mu \mathrm{m}$ long. Pleurocystidia 45-98 $\times 23-77 \mu \mathrm{m}$, clavate to broadly lageniform, thin-walled, hyaline. Cheilocystidia 29-57 $\times$ 9-22 $\mu \mathrm{m}$, clavate to broadly lageniform, thin-walled, hyaline. Hymenophoral trama inverse, made up of thin-walled hyaline hyphae, 5-20 $\mu \mathrm{m}$ wide. Pileipellis a cutis, with terminal elements $37-98 \times 8-16 \mu \mathrm{m}$, variable in size, narrowly clavate to clavate, sometimes with a narrowed or slightly strangulated apex, colorless or with pale brown intracellular pigment. Stipitipellis a cutis, terminal elements $22-60 \times 8-15 \mu \mathrm{m}$, cylindrical, sometimes with a narrowed or slightly strangulated apex, colorless or with pale brown intracellular pigment. Clamp connections absent in all tissue types.

Ecology and distribution: Fruiting solitary or gregarious on soil in grassland. Known only from northern Thailand.

Additional specimens examined: THAILAND, Chiang Mai province, Chiang Mai University campus, $18^{\circ} 48^{\prime} 7^{\prime \prime} \mathrm{N} 98^{\circ} 57^{\prime} 23^{\prime \prime} \mathrm{E}$, elevation $331 \mathrm{~m}$, on soil in grassland, July 2020, N. Suwannarach and J. Kumla, SDBR-CMUNK0760, gene sequences OM417505 (ITS) and OM417507 (nrLSU). 


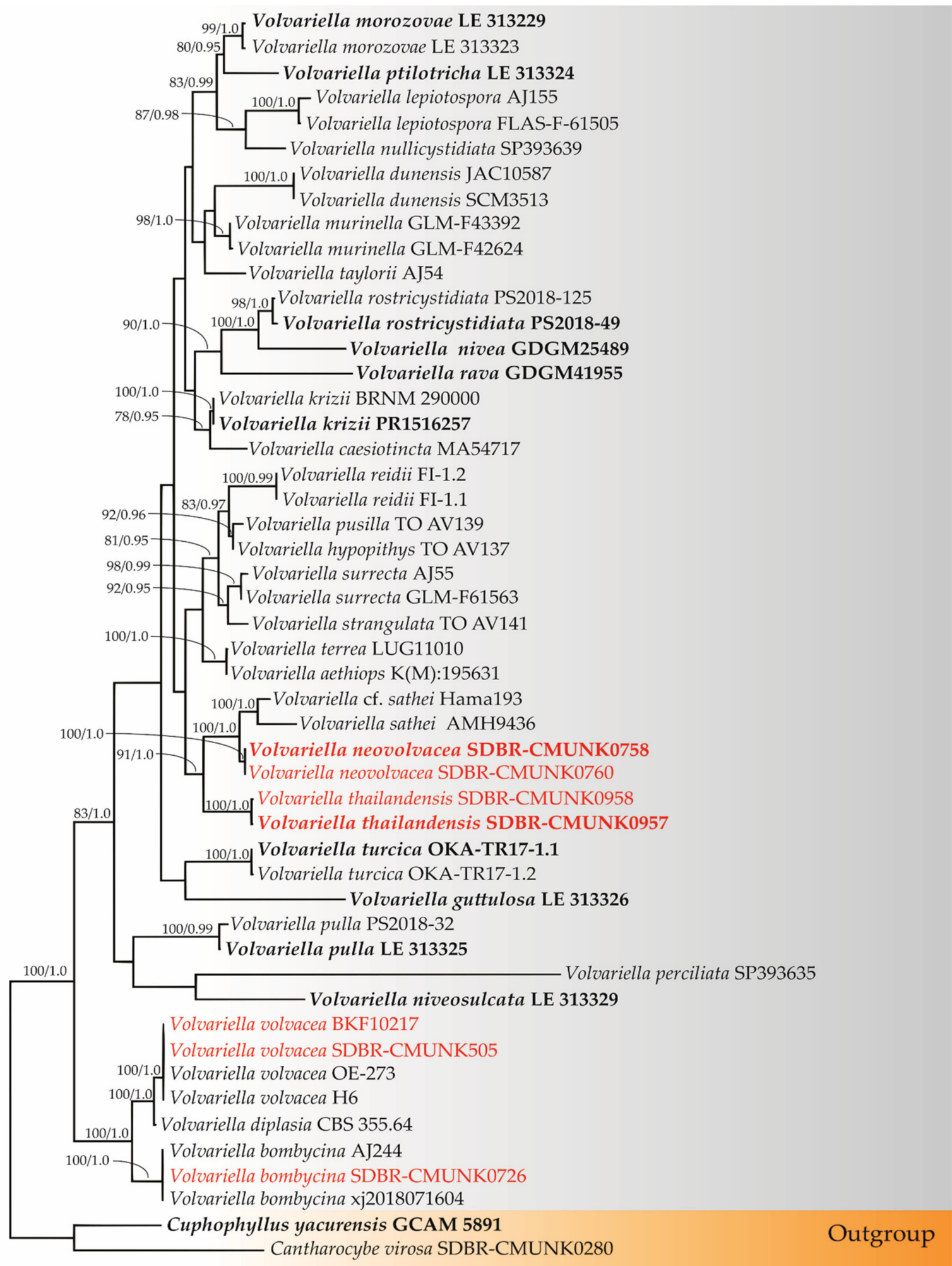

Figure 1. Phylogram derived from maximum likelihood analysis of 50 specimens of the combined ITS and nrLSU genes. Cantharocybe virosa and Cuphophyllus yacurensis were used as the outgroup. The numbers above branches represent bootstrap percentages (left) and Bayesian posterior probabilities (right). Bootstrap values $\geq 75 \%$ and Bayesian posterior probabilities $\geq 0.90$ are shown. The scale bar represents the expected number of nucleotide substitutions per site. Sequences obtained from this study are in red. Type species are in bold. 

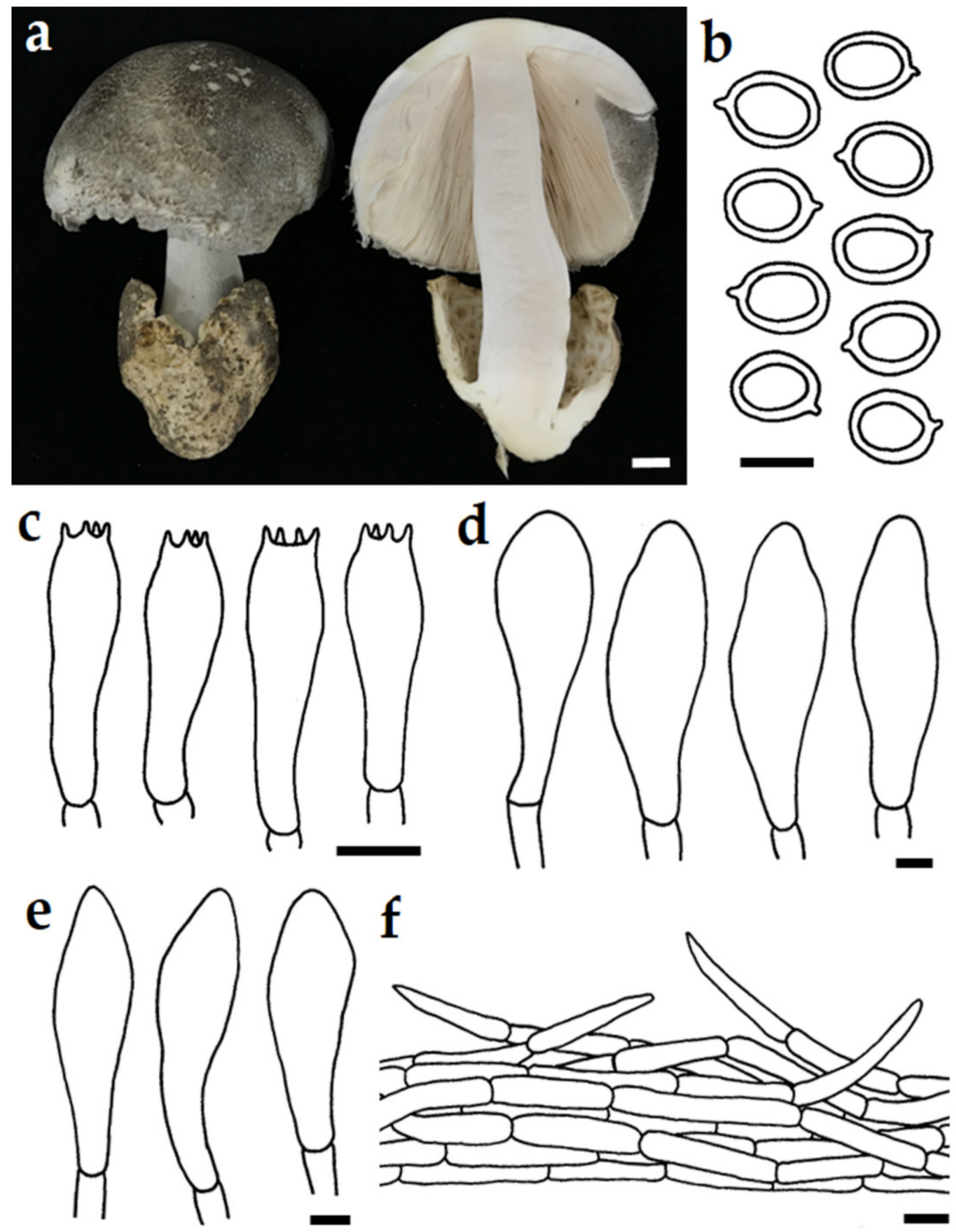

Figure 2. Volvariella neovolvacea SDBR-CMUNK0758 (holotype). Basidiomata (a); Basidiospore (b); Basidia (c); Pleurocystidia (d); Cheilocystidia (e); Pileipellis terminal elements (f). Scale bars: (a) $=10 \mathrm{~mm} ;(\mathbf{b})=5 \mu \mathrm{m} ;(\mathbf{c}-\mathbf{f})=10 \mu \mathrm{m}$.

Note: Morphologically, the size of the pileus $(65-80 \mathrm{~mm}$ in diameter) in $V$. neovolvacea was clearly larger than those of the brownish orange to greyish brown Volvariella species, namely $V$. aethiops (30-50 $\mathrm{mm}$ in diameter) [48], V. caesiotincta (44 $\mathrm{mm}$ in diameter) [49], $V$. morozovae (30-40 $\mathrm{mm}$ in diameter) [32], V. murinella (30-60 $\mathrm{mm}$ in diameter) [50,51], $V$. pseudovolvacea (30-60 $\mathrm{mm}$ in diameter) [9], V. thailandensis (35-60 $\mathrm{mm}$ in diameter), and $V$. taylorii (20-50 $\mathrm{mm}$ in diameter) [51] (Table 2). In addition, V. bakeri, distributed only in the USA, has a larger pileus size (100 $\mathrm{mm}$ in diameter) than $V$. neovolvacea [2,52]. However, the basidiomata size of $V$. neovolvacea was similar to V. pulla, V. rostricystidiata, V. terastia, and $V$. volvacea $[4,6,9,51]$. The smaller size of the basidiospores in $V$. rostricystidiata and $V$. terastia clearly distinguishes them from $V$. neovolvacea [6,9]. Additionally, the basidiospores of $V$. neovolvacea $(6.5-8.0 \times 5.0-7.0 \mu \mathrm{m}, Q=1.28)$ were wider than $V$. volvacea (6.0-9.0 $\times$ 4.7-5.7 $\mu \mathrm{m}, Q=1.42)[9,15]$. The wider size of pleurocystidia in $V$. neovolvacea clearly differed from $V$. pseudovolvacea, $V$. pulla, $V$. rostricystidiata, and V. terastia $[4,6]$. 
Table 2. Comparison of $V$. neovolvacea and $V$. thailandensis with the closely related species.

\begin{tabular}{|c|c|c|c|c|c|c|c|}
\hline $\begin{array}{l}\text { Volvariella } \\
\text { Species }\end{array}$ & Distribution & $\begin{array}{l}\text { Pileus (mm in } \\
\text { Diameter) }\end{array}$ & $\begin{array}{l}\text { Basidiospore } \\
(\mu \mathrm{m})\end{array}$ & $\begin{array}{c}\text { Basidia } \\
(\mu \mathrm{m})\end{array}$ & $\begin{array}{l}\text { Pleurocystidia } \\
(\mu \mathrm{m})\end{array}$ & $\begin{array}{l}\text { Cheilocystidia } \\
(\mu \mathrm{m})\end{array}$ & Reference \\
\hline V. aethiops & France & $30-50$ & $7.0-11 \times 3.7-7.2$ & NR & $60-100 \times 10-25$ & $60-100 \times 10-25$ & [48] \\
\hline V. bakeri & USA & 100 & $6.9-9.3 \times 4.6-6.9$ & $21-35 \times 7-11$ & $47-71 \times 11-31$ & $27-71 \times 11-31$ & {$[2,52]$} \\
\hline V. caesiotincta & $\begin{array}{l}\text { Europe and } \\
\text { North Africa }\end{array}$ & 44 & $6.2-7.7 \times 4.2-5.4$ & $21-28 \times 6.5-9$ & $35-46 \times 10-25$ & $34-65 \times 9.6-19$ & {$[18,49]$} \\
\hline V. morozovae & Vietnam & $30-40$ & $5.0-6.2 \times 3.3-4.3$ & $13.5-20 \times 7-8.5$ & $45-50 \times 18-30$ & $40-50 \times 13-18$ & [32] \\
\hline V. murinella & $\begin{array}{c}\text { Europe } \\
\text { and Vietnam }\end{array}$ & $30-60$ & $4.8-5.6 \times 4.9-6.6$ & $19-25 \times 6-7$ & $20-30 \times 10-15$ & $45-65 \times 8-15$ & {$[50,51]$} \\
\hline V. neovolvacea & Thailand & $65-80$ & $6.5-8.0 \times 5.0-7.0$ & $27-40 \times 7.5-11$ & $45-98 \times 23-77$ & $29-57 \times 9-22$ & This study \\
\hline V. pseudovolvacea & Sri Lanka & $30-60$ & $4.2-5.2 \times 2.5-3.5$ & $14-16 \times 4.5-6.5$ & $32-45 \times 12-16$ & $30-38 \times 12-14$ & [9] \\
\hline V.pulla & $\begin{array}{l}\text { Thailand } \\
\text { and Vietnam }\end{array}$ & $40-75$ & $5.5-8.0 \times 4.0-5.0$ & $16-19.5 \times 7-9$ & $25-56 \times 6-32$ & $24-87 \times 9-17$ & {$[4,6]$} \\
\hline V. rava & China & $25-60$ & $4.0-6.5 \times 4.0-5.0$ & $24-30 \times 7-10$ & $35-71 \times 11-30$ & $55-80 \times 15-25$ & [36] \\
\hline V. rostricystidiata & $\begin{array}{c}\text { Thailand } \\
\text { Europe, South }\end{array}$ & $55-85$ & $5.0-7.0 \times 3.5-5.5$ & $17.5-29 \times 7-10$ & $41-117 \times 10-25$ & $51-80 \times 14-39$ & [6] \\
\hline V. taylorii & $\begin{array}{l}\text { Korea, USA } \\
\text { and Vietnam }\end{array}$ & $20-50$ & $5.0-7.0 \times 3.0-4.8$ & $20-24 \times 6-8$ & $35-49 \times 8-10$ & $28-43 \times 9-13$ & {$[18,51,52]$} \\
\hline$V$. terastia & Sri Lanka & $60-110$ & $5.0-6.5 \times 4.2-5.2$ & $17-23 \times 5.5-7$ & $35-50 \times 15-22$ & $32-36 \times 10-13$ & [9] \\
\hline$V$. thailandensis & Thailand & $35-50$ & $5.5-7.0 \times 4.0-6.0$ & $15-35 \times 6-8$ & $35-77 \times 17-30$ & $32-48 \times 6-10$ & This study \\
\hline$V$. volvacea & $\begin{array}{l}\text { Asia and } \\
\text { East Africa }\end{array}$ & 50-100 & $6.0-9.0 \times 4.7-5.7$ & $30-35 \times 7.5-9.0$ & $45-120 \times 17-30$ & $40-70 \times 10-15$ & $\begin{array}{c}{[9,51],} \\
\text { This study }\end{array}$ \\
\hline
\end{tabular}

Our phylogenetic results from the combined ITS and nrLSU sequences confirmed that $V$. neovolvacea formed a monophyletic clade, which clearly separated it from the other morphologically related Volvariella species (Figure 1). The phylogenetic analysis also supports the determination that $V$. neovolvacea and $V$. volvacea are different species. Volvariella neovolvacea forms a sister taxon to $V$. sathei. However, the white to yellowish white pileus of $V$. sathei clearly separates it from $V$. neovolvacea [38]. The ITS sequence of $V$. neovolvacea is $95.64 \%$ and $94.00 \%$ similar to $V$. sathei (JN792550) and $V$. cf. sathei (KF926663), respectively.

Volvariella thailandensis N. Suwannarach, J. Kumla, and S. Lumyong, sp. nov. Figure 3.

MycoBank: 842647.

Diagnosis: Similar to $V$. taylorii but differing in a wider pleurocystidia and narrower cheilocystidia.

Etymology: Name referred to Thailand, where the new species was found.

Holotype: THAILAND, Chiang Mai province, Chiang Mai University campus, $18^{\circ} 48^{\prime} 22^{\prime \prime} \mathrm{N}$ $98^{\circ} 56^{\prime} 51^{\prime \prime}$ E, elevation $348 \mathrm{~m}$, on soil in grassland, August 2020, J. Kumla and N. Suwannarach, SDBR-CMUNK0957.

Gene sequences (from holotype): OM417510 (ITS) and OM417509 (nrLSU).

Pileus 35-50 $\mathrm{mm}$ in diameter, convex to plano-convex with a low broad umbo, greyish brown (6E3-7E3) with slightly darker color at the center, non-hygrophanous, with fibrillose to appressed squamulose surface; margin decurved to straight, thin, crenulate; context soft, light yellow (4A5). Lamellae free, ventricose, close, moderately thin, soft, pale orange (6A3) turning brownish orange (6C6) with age; edge finely fimbriate, concolorous with faces; lamellulae present, very variable in length, mostly in one tier. Stipe $40-65 \times 4-5 \mathrm{~mm}$, central, tapered from the base to apex, solid, greyish brown (6E3) to dark brown (6F5), slightly paler near the base, entirely pubescent; context light yellow (4A5); annulus absent. Volva 15-18 mm high, thick, mostly free, saccate, fragile, white (6A1) to greyish brown (6D4). Spore print pinkish (7A2).

Basidiospores (5.5)6-7-6.5(7) $\times(4) 4.4-5-5.5(6) \mu \mathrm{m}(\mathrm{n}=50), \mathrm{Q}=1.16-1.50, \mathrm{Q}=1.30 \pm 0.1$, subglobose to broadly ellipsoid, thick-walled, hyaline, inamyloid. Basidia 15-35 $\times 6-8 \mu \mathrm{m}$, narrowly to broadly clavate, hyaline, four-spored; sterigmata up to $3 \mu \mathrm{m}$ long. Pleurocystidia 35-77 $\times 17-30 \mu \mathrm{m}$, broadly fusiform to lageniform, thin-walled, hyaline. Cheilocystidia 32-48 $\times 6-10 \mu \mathrm{m}$, narrowly to broadly clavate, broadly lageniform, thin-walled, hyaline. Hymenophoral trama inverse, made up of thin-walled hyaline hyphae, 3-10 $\mu \mathrm{m}$ wide. Pileipellis a cutis, with terminal elements $65-150 \times 4-16 \mu \mathrm{m}$, variable in size, nar- 
rowly clavate to clavate, sometimes with a narrowed or slightly strangulated apex, colorless or with pale brown intracellular pigment. Stipitipellis a cutis, terminal elements 35-80 $\times 6-9 \mu \mathrm{m}$, cylindrical, sometimes with a narrowed or slightly strangulated apex, colorless or with pale brown intracellular pigment. Clamp connections absent in all tissue types.
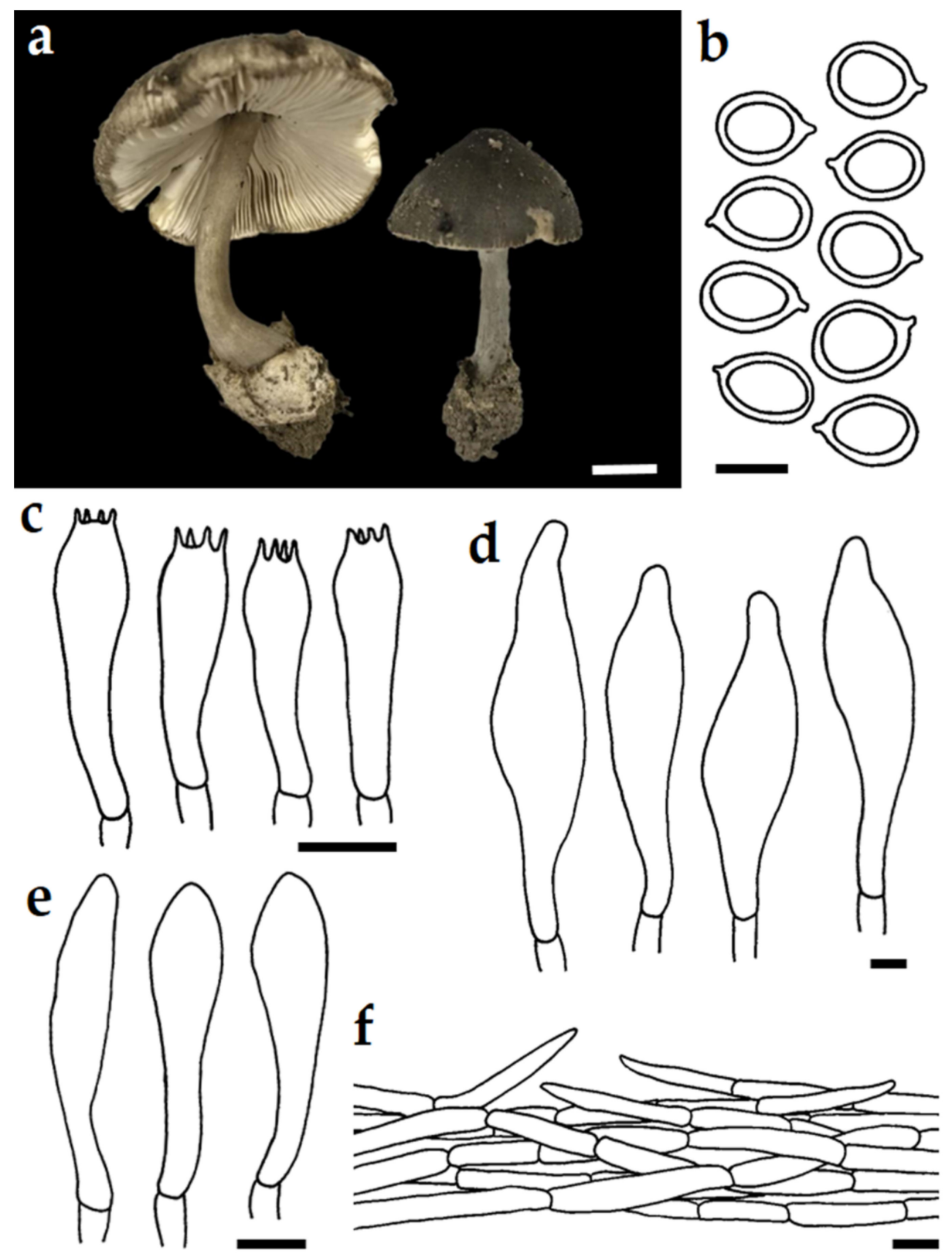

Figure 3. Volvariella thailandensis SDBR-CMUNK0957 (holotype). Basidiomata (a); Basidiospore (b); Basidia (c); Pleurocystidia (d); Cheilocystidia (e); Pileipellis terminal elements (f). Scale bars: (a) $=10 \mathrm{~mm} ;(\mathbf{b})=5 \mu \mathrm{m} ;(\mathbf{c}-\mathbf{f})=10 \mu \mathrm{m}$.

Additional specimens examined: THAILAND, Chiang Mai province, Chiang Mai University campus, $18^{\circ} 48^{\prime} 21^{\prime \prime} \mathrm{N} 98^{\circ} 56^{\prime} 52^{\prime \prime}$ E, elevation $348 \mathrm{~m}$, on soil in grassland, August 2020, J. Kumla and N. Suwannarach, SDBR-CMUNK0958, gene sequences OM417510 (ITS) and OM386669 (nrLSU).

Note: Based on the morphology, the brownish orange to greyish brown pileus and size of $V$. thailandensis were similar to that of $V$. aethiops, $V$. caesiotincta, $V$. morozovae, V. murinella, V. pseudovolvacea, V. rava, and V. taylorii [9,18,32,36,48,50-52] (Table 2). However, the larger size of the basidiospores and basidia in $V$. thailandensis differs from 
$V$. pseudovolvacea [9]. The longer and shorter sizes of basidiospores in $V$. thailandensis clearly distinguishes it from $V$. murinella $[50,51]$ and $V$. aethiops [48], respectively. Additionally, the pleurocystidia $(35-77 \times 17-30 \mu \mathrm{m})$ of $V$. thailandensis were found to be wider than of the V.taylorii $(35-49 \times 8-10 \mu \mathrm{m})$ found in Europe, South Korea, the USA, and Vietnam [18,51,52]. The wider cheilocystidia in $V$. caesiotincta $(34-65 \times 9.6-19 \mu \mathrm{m})[18,49]$, V. morozovae $(40-50 \times 13-18 \mu \mathrm{m})$ [32], V. pulla $(24-87 \times 9-17 \mu \mathrm{m})$ [4,6], V. rava $(55-80 \times$ $15-25 \mu \mathrm{m})[36]$, and $V$. taylorii $(28-43 \times 9-13 \mu \mathrm{m})[18,51,52]$ clearly distinguishes them from $V$. thailandensis $(32-48 \times 6-10 \mu \mathrm{m})$.

The phylogenetic analyses of the combined ITS and nrLSU sequences confirmed that $V$. thailandensis formed a monophyletic clade, which clearly separated it from the other Volvariella species (Figure 1). Volvariella thailandensis is closely related to V. neovolvacea and $V$. sathei. However, it is morphologically quite different from $V$. sathei which has white to yellowish white pileus [38]. Moreover, $V$. thailandensis is characterized by smaller basidiomata and wider cheilocystidia than $V$. neovolvacea (Table 2).

\section{Discussion}

Volvariella is widely distributed in both temperate and tropical areas throughout the world $[2,5-8,53]$. Traditionally, morphological characteristics have been used in the identification of Volvariella species $[5,7,9,11]$. However, identification can be difficult as some species have similar features. Thus, effective identification can be limited by certain morphological characteristics as well as the different environmental conditions that affect those morphological characteristics. Over the last two decades, molecular phylogeny has been an essential tool in the identification of Volvariella species [3,4,6,10,17-19,21,32-39]. Thus, the current classification of the genus Volvariella has been based on the combined data of the morphological characteristics and molecular data.

In 2011, six Volvariella species (V. bombycina, V.cubensis, V. hypopithys, V. pseudovolvacea, $V$. pusilla, and $V$. volvacea) have been recorded by mycologists in Thailand according to their morphological characteristics. However, in this regard, there is a lack of available molecular data [20]. Molecular data of $V$. volvacea from Thai specimen has been reported by $\mathrm{Vu}$ et al. [21]. In 2021, a new species ( $V$. rostricystidiata) and a new record ( $V$. pulla) of Volvariella were reported from Thailand by Niego et al. [6]. In this study, two new species of Volvariella ( $V$. thailandensis and $V$. neovolvacea) and two previously known species ( $V$. bombycina and $V$. volvacea), collected from northern Thailand, were identified based on their morphological characteristics and phylogenetic analyses. Thus, the number of Volvariella species recorded in Thailand has risen to a total of ten species, of which six species were confirmed by morphological and molecular evidence. Nevertheless, four Volvariella species listed by Chandrasrikul et al. [20] require further confirmation by molecular data. To our knowledge, our discovery is considerably important in terms of stimulating a deeper investigation of macrofungi in Thailand, and will help researchers better understand the distribution and ecology of Volvariella.

Author Contributions: Conceptualization, J.K., N.S. and N.W.; methodology J.K. and N.S.; software, J.K.; validation, J.K., N.S., N.W. and S.L.; formal analysis, J.K. and N.W.; investigation, J.K., N.S. and N.W.; resources, J.K., N.S. and N.W.; data curation, J.K., N.S. and N.W.; writing-original draft preparation, J.K. and N.S.; writing—review and editing, J.K. and N.S.; project administration, J.K., N.S. and N.W.; supervision, J.K., N.S., N.W. and S.L. All authors have read and agreed to the published version of the manuscript.

Funding: This research was supported by Chiang Mai University, Thailand.

Institutional Review Board Statement: Not applicable.

Informed Consent Statement: Not applicable.

Data Availability Statement: The DNA sequence data obtained from this study have been deposited in GenBank under accession numbers; ITS (MN492647, OM417503, OM417505, OM417506, OM417508, 


\section{OM417510 and OM417513) and nrLSU (OM373563, OM373623, OM373644, OM373653, OM386669, OM417507 and OM417509).}

Acknowledgments: The authors are grateful to the staff of Si Satchanalai National Park for their excellent field assistance and to Russell Kirk Hollis for kind help in the English correction. The authors are also grateful to Surapong Khuna and Netethip Khamkiti for phylogram preparation.

Conflicts of Interest: The authors declare no conflict of interest.

\section{References}

1. Priest, M.; Conde, B. The occurrence of Volvariella volvacea (Bull.: Fr.) Singer in the Northern Territory, Australia. Australas. Mycol. 2006, 25, 65-67.

2. Shaffer, R. Volvariella in North America. Mycologia 1957, 49, 545-579. [CrossRef]

3. Menolli, N., Jr.; Capelari, M. Records and two new species of Volvariella (Pluteaceae, Agaricales) from Brazil. Mycotaxon 2009, 106, 385-398.

4. Malysheva, E.; Malysheca, V.; Alexandrova, A.; Morozova, O. Observations on Pluteaceae in Vietnam. 1. New species and new records of Volvariella. Phytotaxa 2019, 408, 233-254. [CrossRef]

5. Pegler, D.N. A preliminary agaric flora of East Africa. Kew Bull. Add. Ser. 1977, 6, 1-615.

6. Niego, A.G.T.; Sysouphanthong, P.; Thongklang, N.; Hyde, K.D.; Phonemany, M.; Phokkamsak, R.; Raspé, O. A new species of Volvariella and the first record of Volvariella pulla (Agaricales: Incertae sedis) from Thailand. Phytotaxa 2020, 480, 237-250. [CrossRef]

7. $\quad$ Singer, R. The Agaricales in modern taxonomy. Lilloa 1951, 22, 1-832.

8. Kirk, P.M.; Cannon, P.; Stalpers, J. (Eds.) Dictionary of the Fungi, 10th ed.; CABI: Wallingford, UK, 2008 ; p. 728.

9. $\quad$ Pegler, D.N. Agaric flora of Sri Lanka. Kew Bull. Add. Ser. 1986, 12, 1-519.

10. Justo, A.; Castro, M. The genus Volveriella in Spain: V. dunensis comb. \& stat. nov. and observations on V. Earlei. Mycotaxon 2010, $112,261-270$.

11. Singer, R. The Agaricales in Modern Taxonomy, 4th ed.; Koeltz Scientific Books: Koenigstein, Germany, 1986 ; pp. $455-457$.

12. Orton, P.D. British Fungus Flora, Agarics and Boleti 4-Pluteaceae: Pluteus and Volvariella; Royal Botanic Garden: Edinburgh, UK, 1986; p. 99.

13. Mortimer, P.E.; Bao, E.; Hyde, K.D.; Li, H. Macrofungi as food. Ency. Mycol. 2021, 1, 405-417.

14. Sakinah, N.M.; Misran, A.; Mahmud, T.M.M.; Abdullah, S. A review: Production and postharvest management of Volvariella volvacea. Int. Food. Res. J. 2019, 26, 367-376.

15. Lee, J.Y.; Lee, Y.W.; Lim, J. Coloured Illustrations of Fungi of Korea; Baemunkak: Seoul, Korea, 1959; p. 138.

16. Lee, J.Y. The list of the fungi of Korea. Korean J. Mycol. 1973, 1, 35-43.

17. Matheny, P.B.; Curtis, J.M.; Hofstetter, V.; Aime, M.C.; Moncalvo, J.-M.; Ge, Z.-W.; Yang, Z.-L.; Slot, J.C.; Ammirati, J.F.; Baroni, T.J.; et al. Major clades of Agaricales: A multilocus phylogenetic overview. Mycologia 2006, 98, 982-995. [CrossRef]

18. Justo, A.; Vizzini, A.; Minnis, A.M.; Menolli, N., Jr.; Capelari, M.; Rodríguez, O.; Malysheva, E.; Contu, M.; Ghignone, S.; Hibbett, D.S. Phylogeny of the Pluteaceae (Agaricales, Basidiomycota): Taxonomy and character evolution. Fungal Biol. 2011, 115, 1-20. [CrossRef]

19. He, M.Q.; Zhao, R.L.; Hyde, K.D.; Begerow, D.; Kemler, M.; Yurkov, A.; McKenzie, E.H.C.; Raspé, O.; Kakishima, M.; Sánchez-Ramírez, S.; et al. Notes, outline and divergence times of Basidiomycota. Fungal Divers. 2019, 99, 105-367. [CrossRef]

20. Chandrasrikul, A.; Suwanarit, P.; Sangwanit, U.; Lunyong, S.; Payapanon, A.; Sanoamuang, N.; Pukahuta, C.; Petcharat, V.; Sardsud, U.; Duengkae, K.; et al. Checklist of Mushrooms (Basidiomycetes) in Thailand; Office of Natural Resources and Environmental Policy and Planning: Bangkok, Thailand, 2011; pp. 112-113.

21. Vu, D.; Groenewald, M.; de Vries, M.; Gehrmann, T.; Stielow, B.; Eberhardt, U.; Al-Hatmi, A.; Groenewald, J.Z.; Cardinali, G.; Houbraken, J.; et al. Large-scale generation and analysis of filamentous fungal DNA barcodes boosts coverage for kingdom fungi and reveals thresholds for fungal species and higher taxon delimitation. Stud. Mycol. 2019, 92, 135-154. [CrossRef] [PubMed]

22. Hyde, K.D.; Norphanphoun, C.; Chen, J.; Dissanayake, A.J.; Doilom, M.; Hongsanan, S.; Jayawardena, R.S.; Jeewon, R.; Perera, R.H.; Thongbai, B.; et al. Thailand's amazing diversity: Up to $96 \%$ of fungi in northern Thailand may be novel. Fungal Divers. 2018, 93, 215-239. [CrossRef]

23. Kumla, J.; Suwannarach, N.; Wannathes, W. Hymenagaricus saisamornae sp. nov. (Agaricales, Basidiomycota) from northern Thailand. Chiang Mai J. Sci. 2021, 48, 827-836.

24. Jaichaliaw, C.; Kumla, J.; Vadthanarat, S.; Suwannarach, N.; Lumyong, S. Multigene phylogeny and morphology reveal three novel species and a novel record of Agaricus from northern Thailand. Front. Microbiol. 2021, 12, e650513. [CrossRef]

25. Boonmee, S.; Wanasinghe, D.N.; Calabon, M.S.; Huanraluek, N.; Chandrasiri, S.K.U.; Jones, G.E.B.; Rossi, W.; Leonardi, M.; Singh, S.K.; Rana, S.; et al. Fungal diversity notes 1387-1511: Taxonomic and phylogenetic contributions on genera and species of fungal taxa. Fungal Divers. 2021, 111, 1-335. [CrossRef]

26. Robert, V.; Vu, D.; Amor, A.B.; van de Wiele, N.; Brouwer, C.; Jabas, B.; Szoke, S.; Dridi, A.; Triki, M.; Ben Daoud, S.; et al. MycoBank gearing up for new horizons. IMA Fungus 2013, 4, 371-379. [CrossRef] [PubMed]

27. Kornerup, A.; Wanscher, J.H. Methuen Handbook of Colour, 3rd ed.; Eyre Methuen: London, UK, 1978; pp. 1-252. 
28. White, T.J.; Bruns, T.; Lee, S.; Taylor, J. Amplification and direct sequencing of fungal ribosomal RNA genes for phylogenetics. In PCR Protocols: A Guide to Methods and Applications; Innis, M.A., Gelfand, D.H., Sninsky, J.J., White, T.J., Eds.; Academic Press: San Diego, CA, USA, 1990; Volume 18, pp. 315-322.

29. Vilgalys, R.; Hester, M. Rapid genetic identification and mapping of enzymatically amplified ribosomal DNA from several Cryptococcus species. J. Bacteriol. 1990, 172, 4238-4246. [CrossRef] [PubMed]

30. Edgar, R.C. MUSCLE: A multiple sequence alignment method with reduced time and space complexity. BMC Bioinform. 2004, $5,113$.

31. Kumla, J.; Suwannarach, N.; Lumyong, S. Cantharocybe virosa, first record of the genus in Thailand. Mycotaxon 2018, 133, 481-485. [CrossRef]

32. Crous, P.W.; Wingfield, M.J.; Burgess, T.I.; Carnegie, A.J.; Hardy, G.E.S.J.; Smith, D.; Summerell, B.A.; Cano-Lira, J.F.; Guarro, J.; Houbraken, J.; et al. Fungal Planet description sheets: 625-715. Persoonia 2017, 39, 270-467. [CrossRef] [PubMed]

33. Vizzini, A.; Contu, M.; Justo, A. Additional records of Volvariella dunensis (Basidiomycota, Agaricales): Morphological and molecular characterization. Mycotaxon 2011, 117, 37-43. [CrossRef]

34. Kaygusuz, O.; Knudsen, H.; Türkekul, I.; Çolak, O.F. Volvariella turcica, a new species from Turkey, and a multigene phylogeny of Volvariella. Mycologia 2020, 112, 577-587. [CrossRef]

35. Li, T.H.; Chen, X.L.; Shen, Y.H.; Li, T. 2009. A white species of Volvariella (Basidiomycota, Agaricales) from southern China. Mycotaxon 2009, 109, 255-261.

36. Xu, J.; Li, T.H.; Shen, Y.H.; Zhang, M. Volvariella rava sp. nov. from southern China. Mycotaxon 2015, 130, 857-865. [CrossRef]

37. Daniëls, P.P.; Hama, O.; Fernández, A.F.; García-Pantaleón, F.I.; Barage, M.; Ibrahim, D.; Alcántara, M.R. First records of some Asian macromycetes in Africa. Mycotaxon 2015, 130, 337-359. [CrossRef]

38. Senthilarasu, G.; Sharma, R.; Singh, S. A new species of Volvariella from India. Mycotaxon 2012, 119, 467-476. [CrossRef]

39. Adewoyin, A.G.; Barooah, M.; Oloke, J.K.; Bora, S.S. Identification and physiological properties of a Nigerian strain of Volvariella sp. isolated from oil palm waste. World J. Microbiol. Biotechnol. 2017, 33, 135. [CrossRef]

40. Stamatakis, A. Raxml-vi-hpc: Maximum likelihood-based phylogenetic analyses with thousands of taxa and mixed models. Bioinformatics 2006, 22, 2688-2690. [CrossRef]

41. Miller, M.A.; Holder, M.T.; Vos, R.; Midford, P.E.; Liebowitz, T.; Chan, L.; Hoover, P.; Warnow, T. The CIPRES Portals. CIPRES. 2009. Available online: http:/ / www.phylo.org/sub_sections/portal (accessed on 5 January 2022).

42. Felsenstein, J. Confidence intervals on phylogenetics: An approach using bootstrap. Evolution 1985, 39, 783-791. [CrossRef]

43. Ronquist, F.; Huelsenbeck, J.P. MrBayes 3: Bayesian phylogenetic inference under mixed models. Bioinformatics 2003, 19, 1572-1574. [CrossRef]

44. Darriba, D.; Taboada, G.L.; Doallo, R.; Posada, D. jModelTest 2: More models, new heuristics and parallel computing. Nat. Methods 2012, 9, 772. [CrossRef]

45. Hillis, D.M.; Bull, J.J. An empirical test of bootstrapping as a method for assessing confidence in phylogenetic analysis. Syst. Biol. 1993, 42, 182-192. [CrossRef]

46. Alfaro, M.E.; Zoller, S.; Lutzoni, F. Bayes or bootstrap? A simulation study comparing the performance of Bayesian Markov Chain Monte Carlo sampling and bootstrapping in assessing phylogenetic confidence. Mol. Biol. Evol. 2003, 20, 255-266. [CrossRef]

47. Rambaut, A. FigTree Tree Figure Drawing Tool Version 131, Institute of Evolutionary Biology, University of Edinburgh. Available online: http:/ / treebioedacuk/software/figtree/ (accessed on 8 January 2021).

48. Favre, A.; Vialard, J. Volvariella aethiops nov. sp. Bull. Mycol. Bot. Dauphiné-Savoie 2007, 47, 19-23.

49. Halama, M. Volvariella caesiotincta P.D. Orton, a new species in the mycobiota of Poland. Acta Mycol. 2009, 44, 43-48. [CrossRef]

50. Boekhout, T. Notulae ad floram agaricinam Neerlandicam-XII: Small, saprophytic Volvariella species in the Netherlands. Persoonia 1986, 13, 197-211.

51. Le, H.; Chu, N. New records of genus Volvariella (Pluteaceae) from Cuc Phuong National Park. Vietnam. J. Sci. Technol. Eng. 2018, 60, 81-88. [CrossRef]

52. Seok, S.J.; Kim, Y.S.; Weon, H.Y.; Lee, K.H.; Park, K.M.; Min, K.H.; Yoo, K.H. Taxonomic study on Volvariella in Korea. Mycobiology 2002, 30, 183-192. [CrossRef]

53. Wartchow, F. Volvariella cubensis: A rare neotropical agaric new to South America. Mycotaxon 2009, 107, 181-187. [CrossRef] 